\title{
Effect of Modified Pin Profile and Process Parameters on the Friction Stir Welding of Aluminum Alloy 6061-T6
}

\author{
J. C. Verduzco Juárez, ${ }^{1}$ G. M. Dominguez Almaraz, ${ }^{1}$ \\ R. García Hernández, ${ }^{2}$ and J. J. Villalón López ${ }^{1}$ \\ ${ }^{1}$ Facultad de Ingeniería Mecánica, Universidad Michoacana de San Nicolás de Hidalgo (UMSNH), Santiago Tapia No. 403, \\ Col. Centro, 58000 Morelia, MICH, Mexico \\ ${ }^{2}$ Instituto de Investigaciones Metalúrgicas, UMSNH, Edificio U, Ciudad Universitaria, Gral. Francisco J. Mugica S/N, \\ Felicitas del Rıo, 58030 Morelia, MICH, Mexico
}

Correspondence should be addressed to G. M. Dominguez Almaraz; dalmaraz@umich.mx

Received 10 August 2016; Revised 27 September 2016; Accepted 4 October 2016

Academic Editor: Hongchao Kou

Copyright (C) 2016 J. C. Verduzco Juárez et al. This is an open access article distributed under the Creative Commons Attribution License, which permits unrestricted use, distribution, and reproduction in any medium, provided the original work is properly cited.

This work deals with the effect of a new "bolt-head" pin profile on the friction stir welding performance of the aluminum alloy 6061-T6, compared to traditional pin profiles. Friction stir welding parameters such as the tool rotation speed and the welding speed were investigated together with the different pin profiles; the results show that the new "bolt-head" pin profile leads to better mechanical properties of welded specimens. The pin profiles used in this work were the straight square (SS), straight hexagon (SH), taper cylindrical (TC), and the straight hexagon "bolt-head" (SHBH). It was found that the last pin profile improves the material flow behavior and the uniform distribution of plastic deformation and reduces the formation of macroscopic defects on the welded zone. Mechanical tensile tests on welded specimens were performed to determine the tensile strength: the specimens welded with the SHBH pin profile have shown the highest mechanical properties. An approach is presented for material flow on this aluminum alloy using the SHBH pin profile, which is related to the improvement on the resulting mechanical properties.

\section{Introduction}

The alloy 6061-T6 is the most popular and used of all aluminum alloys; it presents an adequate balance of mechanical properties, cost, and weight. This alloy is used for aerospace and automotive industries under joining and welding requirements [1-4]. The traditional fusion welding methods, such as MIG and TIG, are characterized by high heat dissipation and the transformations of microstructural phases, leading to a number of defects (microporosities, less fine equiaxed recrystallized grain) and thermic instabilities (hardening precipitates), on the joining elements $[5,6]$. For aeronautical application of the 6061-T6 alloy, the laser welding leads to high mechanical properties (reduction of FZ and HAZ, even if porosity may be promoted) and good finishing $[7,8]$; however, the cost is a principal constraint for this welding method.
Friction stir welding is a solid state welding technique which has been developed at the end of 1991 by "The Welding Institute" in the United Kingdom [9]. A nonconsumable rotating tool communicates energy to the two facing surfaces, which may be of the same metallic alloy or different metallic alloys. The rotating movement and the related friction generate heat dissipation between the two facing surfaces, leading to softening of this region and facilitating the high shear plastic deformation and mixing of the material [10-12].

It has been recognized that the principal parameters affecting the bonding strength of FSW and the resulting microstructure are the rotational speed of tool, the welding speed, the axial tool force, and the angle of tool in regard to the welding surface (tilt angle) [13, 14].

The application of this joining technique has been widely used for the aluminum alloy 6061-T6 [15-19]; nevertheless, in this work is presented the effect of a new profile of the pin tool 
to improve the mechanical properties on this material, after the friction stir welding.

The pin profile is a parameter which plays important role during the FSW process, affecting the welding temperature, plastic deformation, the material mixing, the grain size, the welding defects, and so forth [20-22]. Some different pin profiles have been used to investigate their effects on the mechanical properties of welded materials using FSW [2325]. Furthermore, recent investigations are oriented to the determination of the physical and mechanical effects of pin profiles: a model has been proposed for a taped cylindrical pin profile [22], which proposes equations for the heat generation: (a) from the shoulder surface, (b) from the taper probe surface, and (c) from the pin tip surface. The heat generation integral expression for the taper probe surface is

$$
Q_{2}=\int_{0}^{2 \pi} \int_{0}^{l} \omega \cdot r^{2} \cdot \tau_{\text {contact }} \cdot d z \cdot d \theta
$$

with the solution

$$
\mathrm{Q}_{2}=\frac{\pi \cdot \omega \cdot \tau_{\text {contact }}}{2} \frac{H_{\text {probe }}}{\cos \alpha}\left(R_{\mathrm{PS}}+R_{\mathrm{PT}}\right)^{2},
$$

where $\omega$ is the angular velocity, $\tau_{\text {contact }}$ is the contact stress, $H_{\text {probe }}$ is the vertical length of taper cylindrical pin, $\alpha$ is the taper angle, $R_{\mathrm{PS}}$ is the bottom radius of the pin, $R_{\mathrm{PT}}$ is the top radius of the pin, and $l$ is the inclined length of the pin: $l=H_{\text {probe }} / \cos \alpha$.

Equation (1) is obtained considering $r$ independent of $z$ (along the vertical axis of the pin), which is not the case. Here, we propose $r$ as a function of $z: r=R_{\mathrm{PT}}-z \tan \alpha$; the integral equation (1) becomes

$$
\begin{aligned}
Q_{2} & =\int_{0}^{2 \pi} \int_{0}^{H_{\text {probe }}} \omega \cdot \tau_{\text {contact }} \\
& \cdot\left(R_{\mathrm{PT}}^{2}-2 R_{\mathrm{PT}} \cdot z \tan \alpha+z^{2} \cdot \tan ^{2} \alpha\right) d z \cdot d \theta .
\end{aligned}
$$

With $H_{\text {probe }} \tan \alpha=R_{\mathrm{PT}}-R_{\mathrm{PS}}$, the solution is

$$
\mathrm{Q}_{2}=2 \pi \cdot \omega \cdot \tau_{\text {contact }} \frac{H_{\text {probe }}}{3}\left(R_{\mathrm{PT}}^{2}+R_{\mathrm{PT}} \cdot R_{\mathrm{PS}}+R_{\mathrm{PS}}^{2}\right) .
$$

Equation (4) gives values slightly lower compared to (2) for the taper probe surface. The principal conclusion of [22] is that temperature registered during FSW process decreases with the taper angle.

Analytical models for heat generation were obtained for the pins: triangular, square, pentagonal, and hexagonal profiles [26], with the following principal conclusions: (a) heat generation increases from the triangular to square profile; then, it decreases to hexagonal pin profile; (b) increase on the tool rotation speed under constant weld speed induces heat generation increase; (c) the increase on the weld speed, under constant tool rotation speed, leads to decrease on heat generation. These conclusions are not in the same direction in regard to the results obtained for straight and taper cylindrical pin profiles [27], in which heat generation increases with angular speed $\omega$ (the tool rotation speed) and
TABLE 1: Chemical composition in weight of aluminum alloy AISI 6061-T6.

\begin{tabular}{lc}
\hline $\mathrm{Al}$ & 95.8 to 98.6 \\
$\mathrm{Cr}$ & 0.04 to 0.35 \\
$\mathrm{Cu}$ & 0.15 to 0.4 \\
$\mathrm{Fe}$ & Max. 0.7 \\
$\mathrm{Mg}$ & 0.8 to 1.2 \\
$\mathrm{Mn}$ & Max. 0.15 \\
$\mathrm{Si}$ & 0.4 to 0.8 \\
$\mathrm{Ti}$ & Max. 0.15 \\
$\mathrm{Zn}$ & Max. 0.25 \\
& Ether \\
& Total max. 0.05 \\
\hline
\end{tabular}

TAble 2: Principal mechanical properties of aluminum alloy AISI 6061-T6.

\begin{tabular}{lc}
\hline Density $(\mathrm{kg} / \mathrm{m} 3)$ & 2700 \\
Hardness, Brinell & 95 \\
$\sigma_{y}(\mathrm{MPa})$ & 270 \\
$\sigma_{u}(\mathrm{MPa})$ & 310 \\
$E(\mathrm{GPa})$ & 68.9 \\
Poisson ratio & 0.33 \\
Elongation at break $(\%)$ & 17 \\
\hline
\end{tabular}

with the tangential speed $V$ (welding speed). Recently, small tool pin profiles have been investigated using FSW on the 6061 aluminum alloy [28], with better results on mechanical properties for the triangular pin profile compared to the threaded tapered cylindrical and square pin profiles.

\section{Experimental Set-Up and Procedure}

The chemical composition in weight and the principal mechanical properties of aluminum alloy 6061-T6 are shown in Tables 1 and 2, respectively.

Plates of dimensions $200 \mathrm{~mm} \times 150 \mathrm{~mm} \times 9.5 \mathrm{~mm}$ were used for the FSW purpose. The classification of the FSW tests according to the welding parameters for this work is shown in Table 3, whereas in Table 4 are listed the pins profiles and their dimensions.

Heat generation is increased with the shoulder diameter because the area of friction is increased; the effect of this parameter was not studied in this work. Figure 1 presents the four pin profiles used in this investigation; the $\mathrm{PSHBH}$ nomination represents the "bolt-head" pin, previous to manufacture of the bolt-head at the end of the pin. The dimensions of the "bolt-head" pin are shown in Figure 2, whereas in Figure 3 are depicted the welding plates rigidly clamped to the machine bed without any obstruction for the rotation and translation motion of the pin. The alignment of welding line and pin center was maintained close to zero deviation and all tests were carried out with 0 degrees for the tool tilt angle. The FSW process was implemented in a vertical machining center: Dyna Myte/DM-4800 equipped 
TABLE 3: Classification of FSW tests, according to the welding parameters.

\begin{tabular}{lccccc}
\hline $\begin{array}{l}\text { Nomination } \\
\text { test }\end{array}$ & $\begin{array}{c}\text { Tool } \\
\text { rotational } \\
\text { speed }(\mathrm{rpm})\end{array}$ & $\begin{array}{c}\text { Welding } \\
\text { speed } \\
(\mathrm{mm} / \mathrm{min})\end{array}$ & $\begin{array}{c}\text { Penetration } \\
\text { speed } \\
(\mathrm{mm} / \mathrm{min})\end{array}$ & $\begin{array}{c}\text { Axial force } \\
(\mathrm{kN})\end{array}$ & $\begin{array}{c}\text { Used pin } \\
\text { profile }\end{array}$ \\
\hline $\mathrm{C} 1$ & 800 & 40 & 3 & 8 & $\mathrm{SS}, \mathrm{SHBH}$ \\
$\mathrm{C} 2$ & 1000 & 90 & 9 & 8 & $\mathrm{~T}$ \\
$\mathrm{C} 3$ & 1200 & 90 & 9 & 8 & $\mathrm{SH}, \mathrm{SHBH}$ \\
\hline
\end{tabular}

TABLE 4: Models for the pins according to the tool profile, the material, and dimensions.

\begin{tabular}{lccccc}
\hline Models & Pin profile & Shoulder surface & Material & Pin length $(\mathrm{mm})$ & Shoulder diameter $(\mathrm{mm})$ \\
\hline M1 & SS & Flat & Steel 4140 & 9 & 19 \\
M2 & TC & Flat & Steel 4140 & 9 & 19 \\
M3 & SH & Flat & Steel 9840 & 9 & 25.4 \\
M4 & SHBH & Flat & Steel H-13 & 9 & 25.4 \\
\hline
\end{tabular}

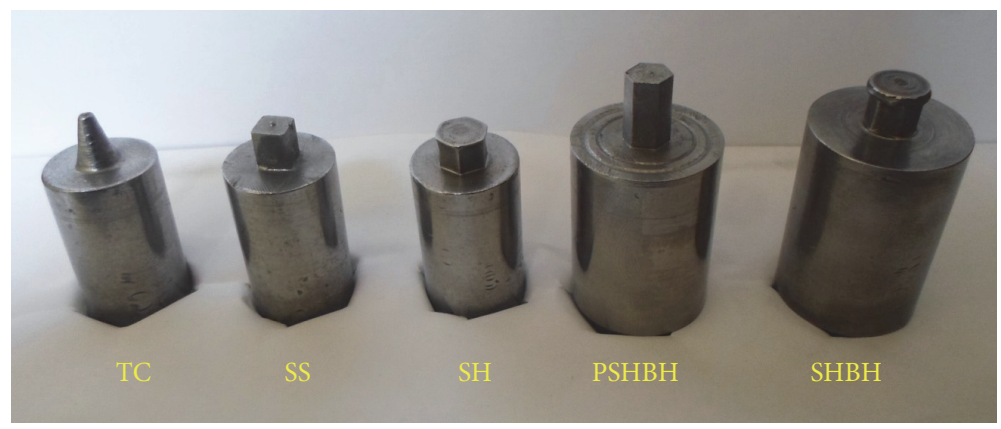

FIGURE 1: Manufactured pin profiles for the FSW process.
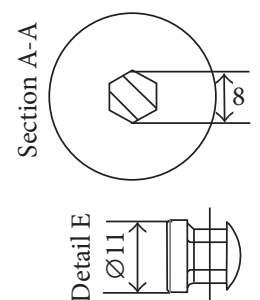
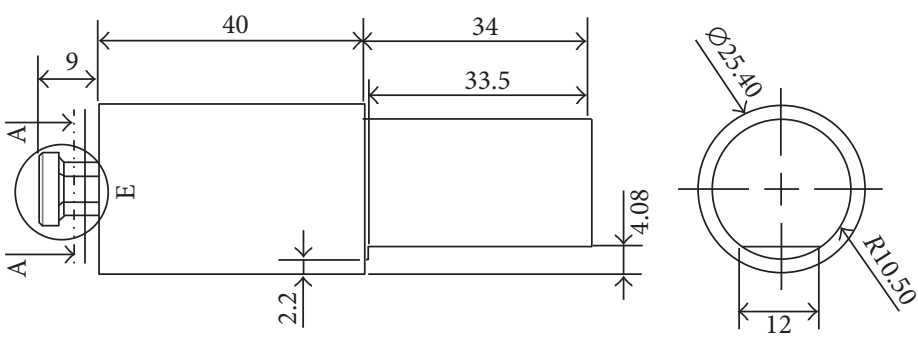

FiguRE 2: Dimensions (mm) for the "bolt-head" pin profile.

with Mitsubishi controls and a maximum tool rotation of $6000 \mathrm{rpm}$.

The testing specimens were obtained from the welded plates in perpendicular direction in regard to the FSW line for the tests: tensile, hardness, and the microstructural observation by optical microscope. Tensile specimens were manufactured according to the norm ASTM-E8M, with a gauge length of $64 \mathrm{~mm}$, a gauge width of $6 \mathrm{~mm}$, and a thickness of $9.5 \mathrm{~mm}$, as shown in Figure 4.

All tensile tests were carried out on a tension machine model Zwick/Roell Z100 with $100 \mathrm{KN}$ of maximum test load and at constant test displacement of $6 \mathrm{~mm} / \mathrm{min}$. The microhardness Mitutoyo model HM 200 was used to obtain the hardness profiles along the welding zone with an applied load of $0.1 \mathrm{Kg}$ and $10 \mathrm{sec}$ of time application. In addition, the FSW welding process was obtained under the following condition: the distance between the tip of pin and the bottom of the welding workpiece was $0.3 \mathrm{~mm}$.

\section{Results and Discussions}

Plates of thickness $9.5 \mathrm{~mm}$ of aluminum alloy 6061-T6 were joined by FSW technique using classical pin profiles ( $\mathrm{SS}, \mathrm{SH}$, and TC) and the new pin profile "bolt-head" to compare the results on welding and mechanical properties [29]. In Figure 5 are illustrated the different zones, from 1 to 8 , along the welding line from which the tensile specimens have been machined. This figure shows the welding direction as well as 
TABLE 5: Tensile tests for specimens welded by the SHBH pin profile and base material (BM) specimens.

\begin{tabular}{|c|c|c|c|c|c|}
\hline $\begin{array}{l}\text { Nomination } \\
\text { test-tool }\end{array}$ & $\begin{array}{l}\text { Specimen } \\
\text { ID-section } \\
\text { (Figure 5) }\end{array}$ & $\begin{array}{l}\text { Stress at } 0.2 \% \\
\text { plastic strain } \\
(\mathrm{MPa})\end{array}$ & $\begin{array}{c}\text { Ultimate } \\
\text { tensile stress } \\
(\mathrm{MPa})\end{array}$ & $\begin{array}{c}d L \text { at break } \\
(\%)\end{array}$ & $\begin{array}{c}\text { Fracture } \\
\text { localization }\end{array}$ \\
\hline C1-M1 & $1-3$ & 113 & 146 & 4.7 & HAZ \\
\hline C1-M1 & $1-4$ & 118 & 150 & 6.2 & HAZ \\
\hline $\mathrm{C} 2-\mathrm{M} 2$ & $2-3$ & 115 & 128 & 3.8 & TMAZ \\
\hline C3-M3 & $3-2$ & 110 & 125 & 3.9 & TMAZ \\
\hline C3-M3 & $3-3$ & 106 & 108 & 4.0 & TMAZ \\
\hline C3-M3 & $3-4$ & 108 & 129 & 6.6 & TMAZ \\
\hline C1-M4 & $4-2$ & 114 & 161 & 10.2 & NHAZ \\
\hline C1-M4 & $4-4$ & 115 & 163 & 10.8 & NHAZ \\
\hline C3-M4 & $5-2$ & 114 & 176 & 10.5 & NHAZ \\
\hline C3-M4 & $5-4$ & 124 & 177 & 9.5 & NHAZ \\
\hline C1-M4 & $6-2$ & 111 & 162 & 11.1 & NHAZ \\
\hline C1-M4 & $6-4$ & 111 & 162 & 11.3 & NHAZ \\
\hline C2-M4 & $7-2$ & 119 & 161 & 8.7 & NHAZ \\
\hline C2-M4 & $7-3$ & 116 & 172 & 5.8 & NHAZ \\
\hline C2-M4 & $7-4$ & 115 & 176 & 9.0 & NHAZ \\
\hline C2-M4 & $8-2$ & 116 & 169 & 4.3 & NHAZ \\
\hline C2-M4 & $8-3$ & 115 & 171 & 9.6 & NHAZ \\
\hline C2-M4 & $8-4$ & 116 & 176 & 10.0 & NHAZ \\
\hline- & BM-1 & 289 & 309 & 14.2 & - \\
\hline- & BM-2 & 296 & 316 & 11.5 & - \\
\hline- & BM-3 & 286 & 308 & 14.2 & - \\
\hline
\end{tabular}

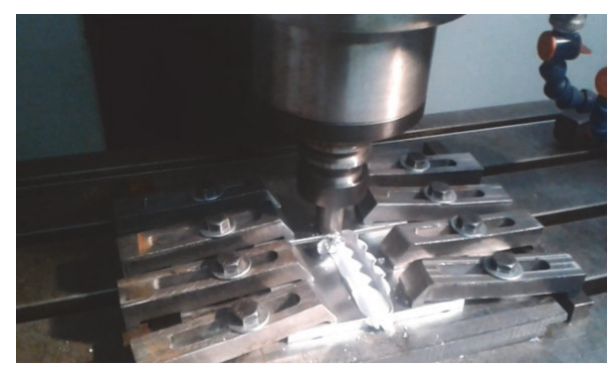

FIGURE 3: The two welding plates clamped to machine bed and the welding tool at the end of the FSW process.

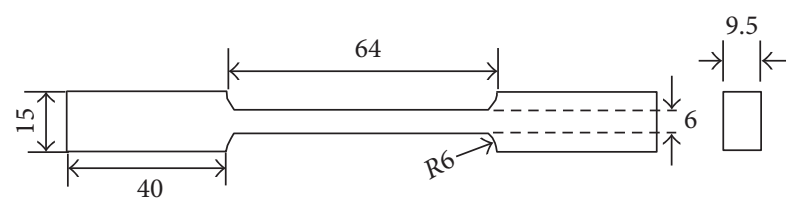

FIGURE 4: Tensile specimen dimensions ( $\mathrm{mm}$ ), following the norm ASTM-E8M.

the advancing and retreating sides and the direction of tool rotation.

The tensile specimens were obtained from the zones 2 to 4 ; the zones 1 and 8 were eliminated for this purpose. Figure 6 presents the macrostructure of the transverse welding zone for the different used pin profiles in function of the rotational

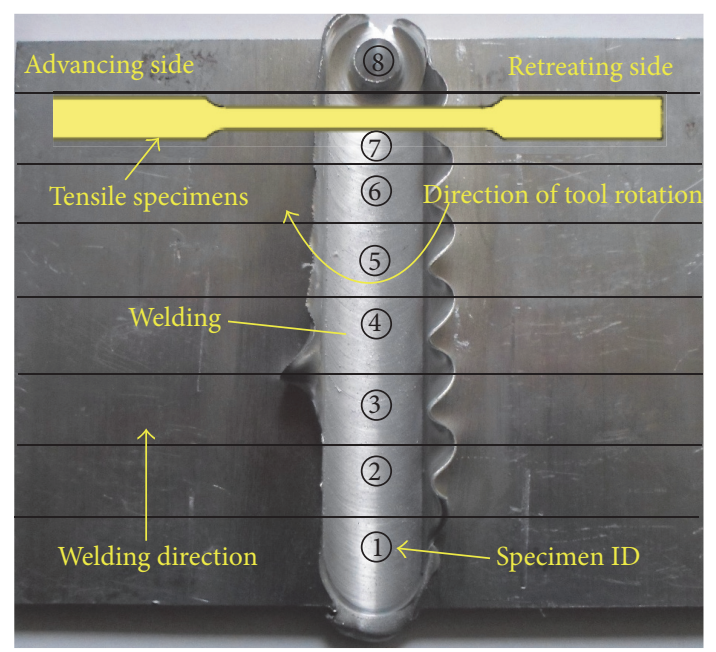

FIGURE 5: Zones for the tensile specimen along the welding line. Direction of welding, advancing and retreating sides, and direction of tool rotation.

speed of tool and the welding speed. The tunnel defect is observed for the pin profiles, SS, TC, and SH, for the three rotating speeds of tool $(800,1000$, and $1200 \mathrm{rpm})$ and for both welding speeds ( 40 and $90 \mathrm{~mm} / \mathrm{min}$ ). The use of low rotational speed and low welding speed with the pin profile SS induces middle ultimate tensile stress on the tensile specimens (146-150 MPa, Table 5); whereas in increasing the 


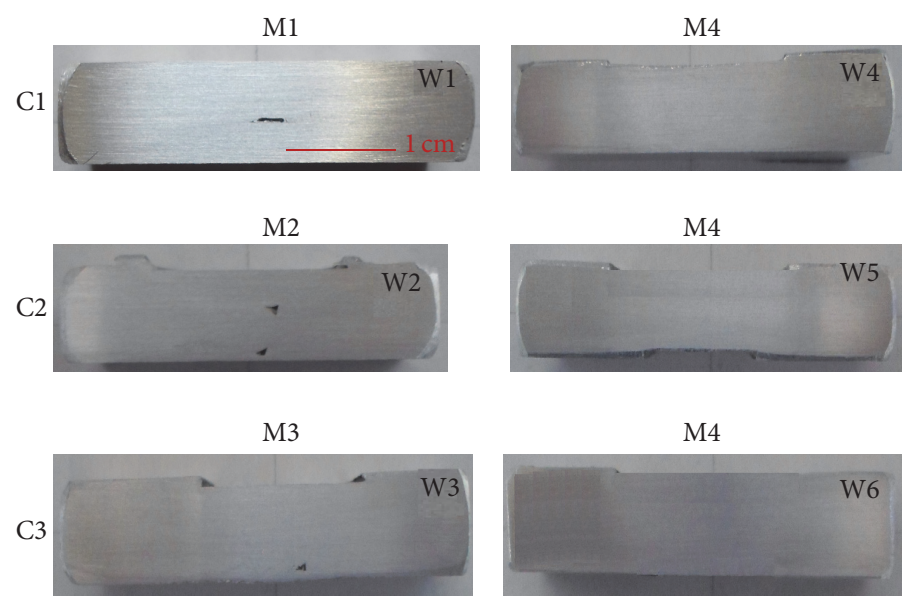

Figure 6: Tunnel defect for welding specimens using different pin profiles, for three tool rotating speeds and two welding speeds.

last two velocities and using the pin profiles TC and $\mathrm{SH}$, the ultimate tensile stress decreases as shown on the same table. The maximum ultimate tensile stress is obtained with the SHBH pin profile (176-177 MPa), using high values for the two weld speeds.

Concerning the tunnel defect in the welded specimens, it is present for the three pin profiles, SS, TC, and SH, as shown in Figure 6; nevertheless, this defect is eliminated using the $\mathrm{SHBH}$ pin profile for all rotating and welding used speeds, as depicted in the same figure. An attempt to explain the causes that induce the elimination of tunnel defect with the use of $\mathrm{SHBH}$ pin profile is undertaken in the last section. These results seem to agree with the physical conditions close to the contact zone between the pin and the welding material: the heat generation increases when the tool rotation speed increases; then, the flow of material across the welding thickness increases too. For tapered pin profiles particularly, the contact area of pin decreases with the depth of the welding thickness and the flow of material increases across the thickness, contributing to tunnel defect.

In Table 5 are listed the tensile tests for the welded specimens using the four pin profiles, as well as the tensile tests on the base material (last three specimens in this table). The ultimate tensile stress for the welded specimens ranges from 108 to $177 \mathrm{MPa}$, whereas for the base material these values range from 308 to $316 \mathrm{MPa}[30,31]$.

Figure 7 presents the tensile tests graphs for the welded specimens and the base material with the following identification in regard to Table 5: C1-M1 = W1-3 (146 MPa UTS); C2M2 = W2-3 (128 MPa UTS); C3-M3 = W3-3 (108 MPa UTS); C1-M4 = W4-3 (163 MPa UTS); C2-M4 = W5-4 (176 MPa UTS); C3-M4 = W6-4 (177 MPa UTS). In all cases for tensile tests on welded specimens, the higher values for UTS were obtained with the $\mathrm{SHBH}$ pin profile. Furthermore, the fracture sites under tensile tests of welded $\mathrm{SHBH}$ specimens were located outside the welding zone, as shown in Figure 8.

Figure 9 presents the Vickers microhardness measured along the weld cross-section comprising the zones: the nugget zone (NZ), the thermomechanical heat zone (TMHZ), the heat affected zone (HAZ), and the base metal (BM), for the welded SHBH specimens. The higher values of this mechanical property have been obtained for low rotation speed during the FSW process and intermediate values for welding speed; this tendency has been mentioned by some authors $[32,33]$, for aluminum alloys.

Fracture surfaces for the tensile specimens are shown in Figure 10: the corresponding fracture surface for specimens containing the tunnel defect is depicted in Figure 10(a), whereas the fracture surface for specimen without the tunnel defect is presented in Figure 10(b). Figure 10(c) shows the fracture surface for the base material. Low plastic deformation characterizes the separation of fracture surfaces for specimens with tunnel defect, revealing that low resistance is opposed to tensile loading: this behavior is represented by the tensile tests W2-3 and W3-3 in Figure 7.

The increase of plastic strain is related to the ductile fracture and the microvoids coalescence, which is observed on this aluminum alloy for tensile specimens presenting higher resistance, as illustrated on Figures 10(b) and 10(c). In this case, the peripheral plastic deformation zone increases with the UTS of tensile test on this material, as it is observed in the last two figures. The central zone of fracture surfaces for specimens without tunnel defect is typified by low or null plastic deformation and a granular nondeformed microstructure [34].

The material flow during the FSW process is a principal factor influencing the presence of welding defects, such as cavities, root flaws, and kissing bond [35]. Generally speaking, the material flow in FSW is determined by three different motions: (a) the material flow beneath and deeper of the tool shoulder, from and to the root of the probe, (b) the flow of material along the pin surface, downward in the vertical direction, and (c) the material flow from the bottom of pin towards the shoulder, away from the pin surface; this flow interacts with the two precedents flows [36, 37].

A swirl is present in the advancing side which increases with the welding speed and induces the radial motion illustrated, whereas in the retreating side the radial motion is considerably reduced and may change direction according to the welding parameters and the testing material $[38,39]$. 

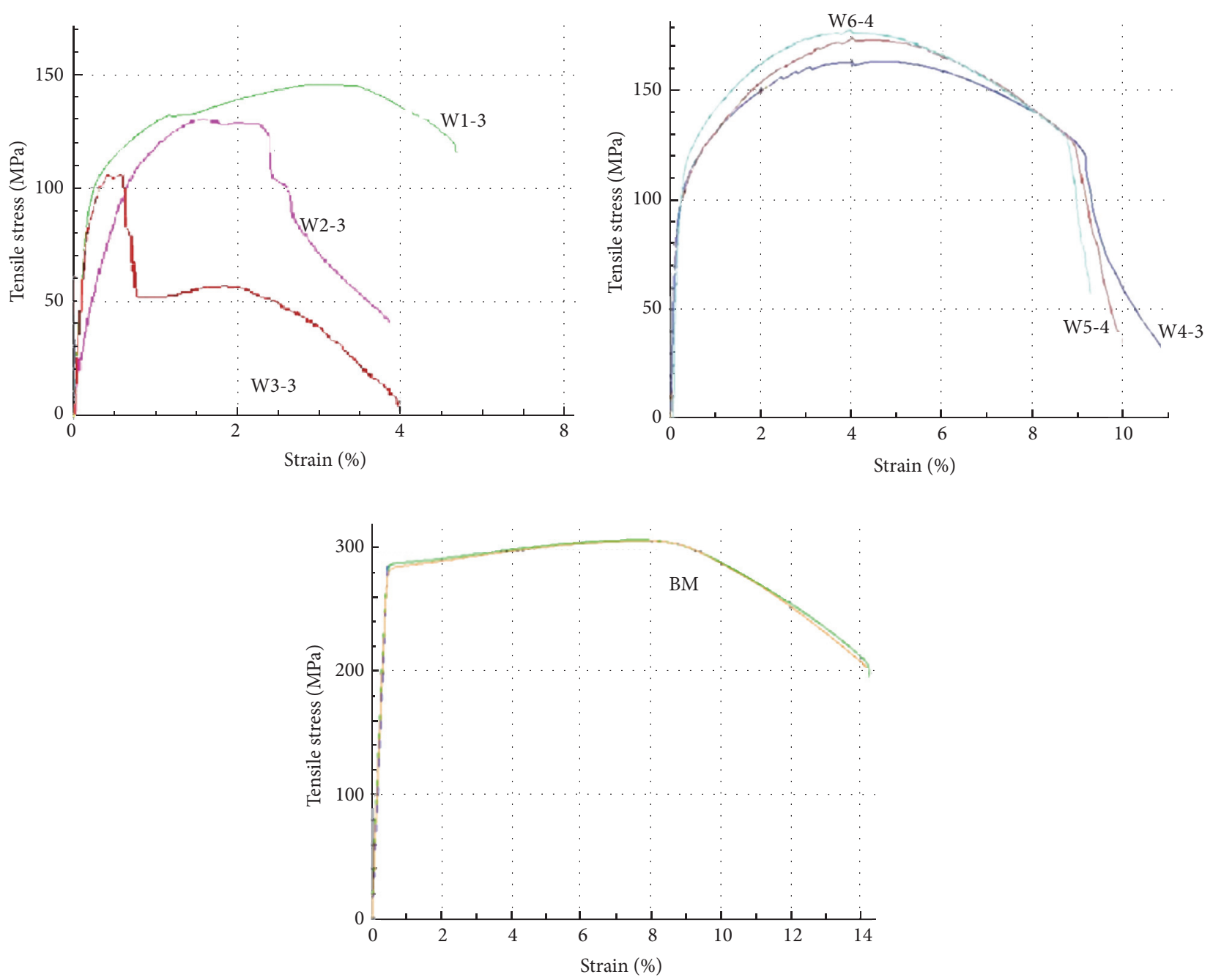

FIgURE 7: Tensile tests for welded and base material specimens.

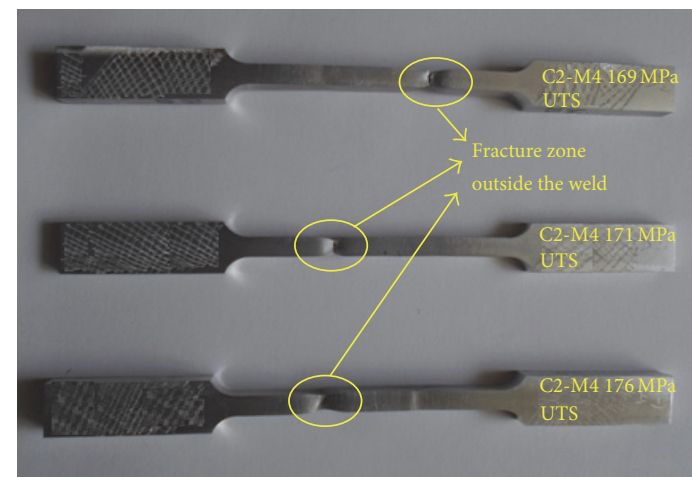

FIGURE 8: Localization of fracture under tensile tests for the SHBH welded specimens.

In Figure 11 are represented the three mentioned flows, contributing to the flow of material during the welding process by FSW.

The flow of material along the pin surface and in the downwards vertical direction is reduced using the SHBH pin

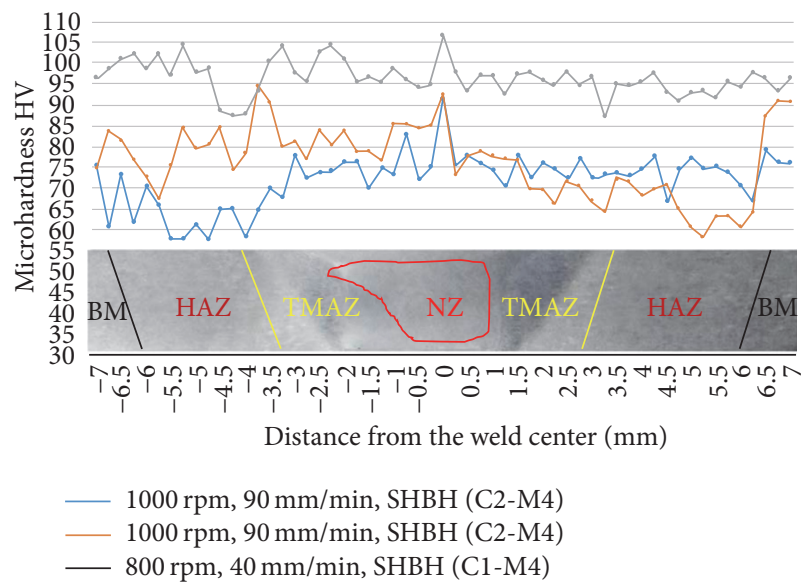

FIGURE 9: Vickers microhardness along the welding zone for the SHBH welded specimens.

profile, whereas the flow from the bottom of pin towards the shoulder is moved more away from the pin surface. The 


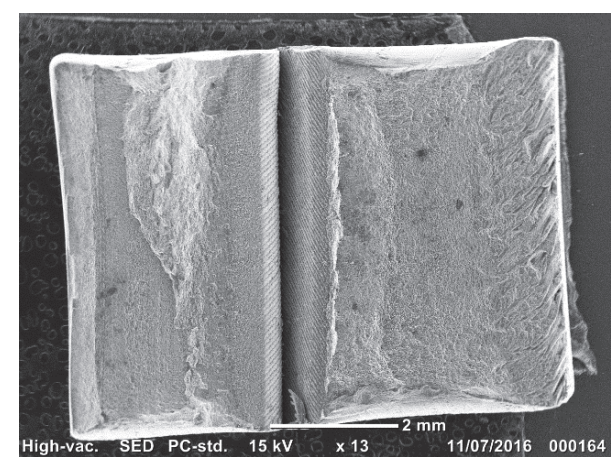

(a)

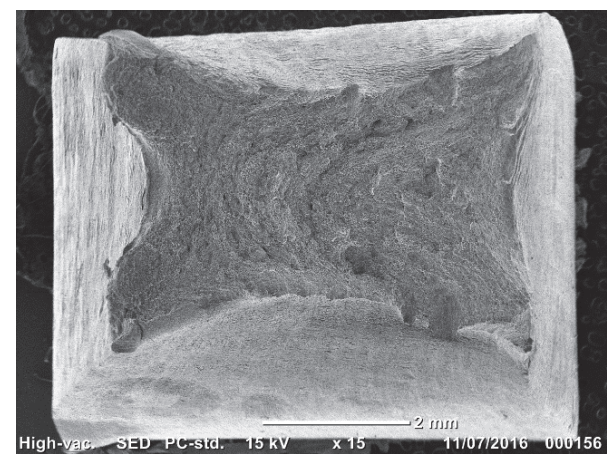

(b)

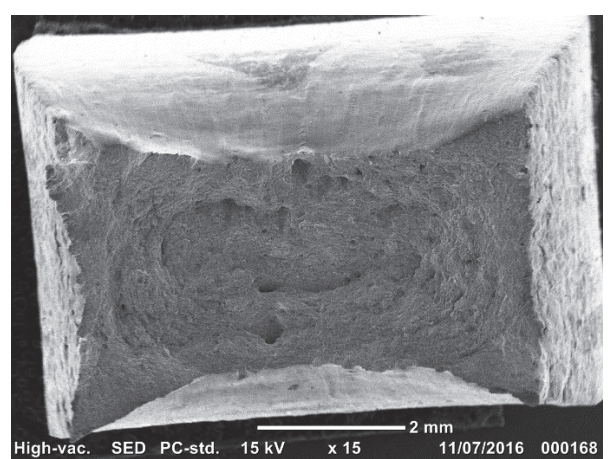

(c)

FIGURE 10: Fracture surfaces for tensile specimens: (a) with tunnel defect, (b) without tunnel defect, and (c) for the base material.

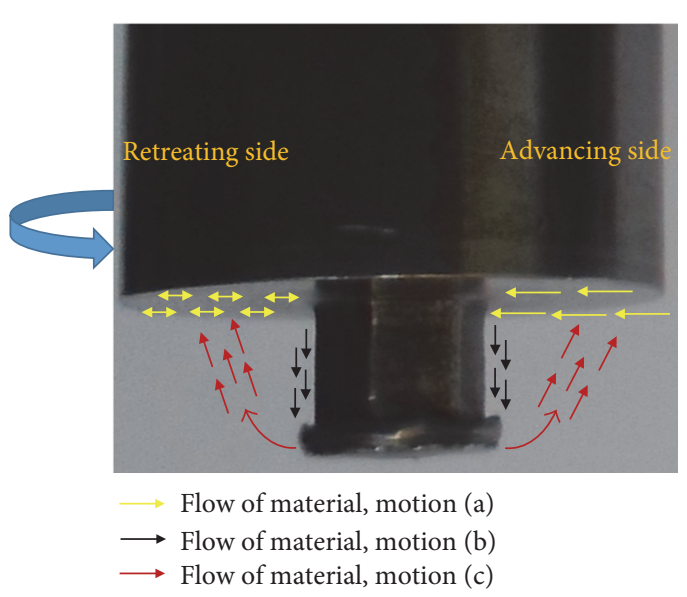

FIGURE 11: Material flows on the SHBH pin profile according to three principal motions.

bolt-head at the end of the pin reduces considerably the material flow in vertical direction: the mechanical effect is the reduction of discontinuities on the material with the rotating and the advancing motion, which leads to reduction of tunnel and other defects in this aluminum alloy. The vertical flow is associated with the continuity of material along the vertical direction during local FSW stirring; the reduction of this flow by the pin bolt-head induces the reduction of material discontinuity and hence welding defects.

\section{Conclusion}

In this work is presented a new pin profile denominated bolthead, for the friction stir welding of the aluminum alloy 6061T6. The tensile and hardness tests show that this pin profile improves such mechanical properties of the welded alloy. Additional conclusions related to this work are as follows:

(a) No tunnel defect was observed on the welded specimens using the SHBH pin profile, for the three rotating speeds and two welding speeds of experimental testing.

(b) A modified expression is proposed to calculate heat generation from the taper probe surface.

(c) The fracture for tensile specimens, using the $\mathrm{SHBH}$ pin profile, took place systematically outside the welding zone.

(d) The Vickers microhardness along the welding zone for the SHBH welded specimens was higher when using low rotational speeds of tool, for the testing welding speeds [40].

(e) Low plastic deformation is observed for the fracture surfaces of specimens with tunnel defect, indicating that low resistance is opposed during the tensile tests. The fracture surface of tensile specimens without tunnel defect shows appreciable plastic deformation around the peripheric rectangular area, indicating resistance of material to tensile loading. 
(f) The bolt-head at the end of the pin reduces the material flow downward, contributing to reduction or elimination of the tunnel and other defects.

(g) Further investigations will be undertaken in the future to assess the effect of the bolt-head profile on the mechanical properties of joining materials by the FSW method, particularly, the heat generation, the material flow, modification of the bolt-head profile, the welding of other materials than aluminum alloys, and so forth.

\section{Competing Interests}

The authors declare that they have no competing interests.

\section{Acknowledgments}

The authors express their gratitude to the University of Michoacan in Mexico for the facilities received in the development of this work. A special mention of gratitude was made to CONACYT (The National Council for Science and Technology, Mexico) for the financial support destined to this study by the Program Grant CB-241117-2014.

\section{References}

[1] F. Fadaeifard, F. Gharavi, K. A. Matori, A. R. Daud, M. K. Ariffin, and M. Awang, "Investigation of microstructure and mechanical properties of friction stir lap welded AA6061-T6 in various welding speeds," Journal of Applied Sciences, vol. 14, no. 3, pp. 221-228, 2014.

[2] L. Liu, H. Nakayama, S. Fukumoto, A. Yamamoto, and H. Tsubakino, "Microscopic observations of friction stir welded 6061 aluminum alloy," Materials Transactions, vol. 45, no. 2, pp. 288-291, 2004.

[3] W. S. Miller, L. Zhuang, J. Bottema et al., "Recent development in aluminium alloys for the automotive industry," Materials Science and Engineering: A, vol. 280, no. 1, pp. 37-49, 2000.

[4] A. Heinz, A. Haszler, C. Keidel, S. Moldenhauer, R. Benedictus, and W. S. Miller, "Recent development in aluminium alloys for aerospace applications," Materials Science and Engineering A, vol. 280, no. 1, pp. 102-107, 2000.

[5] S. Jannet, K. Mathews, and R. Raja, "Comparative investigation of friction stir welding and fusion welding of 6061 T6$5083 \mathrm{O}$ aluminum alloy based on mechanical properties and microstructure," Bulletin of the Polish Academy of Sciences: Technical Sciences, vol. 62, no. 4, pp. 791-795, 2014.

[6] R. Adalarasan and R. M. Santhanakumar, "Parameter design in fusion welding of AA 6061 aluminium alloy using desirability grey relational analysis (DGRA) method," Journal of The Institution of Engineers (India): Series C, vol. 96, no. 1, pp. 57-63, 2015.

[7] A. El-Batahgy and M. Kutsuna, "Laser beam welding of AA5052, AA5083, and AA6061 aluminum alloys," Advances in Materials Science and Engineering, vol. 2009, Article ID 974182, 9 pages, 2009.

[8] D. Narsimhachary, R. N. Bathe, G. Padmanabham, and A. Basu, "Influence of temperature profile during laser welding of aluminum alloy 6061 T6 on microstructure and mechanical properties," Materials and Manufacturing Processes, vol. 29, no. 8, pp. 948-953, 2014.
[9] W. M. Thomas, E. D. Nicholas, J. C. Needham, M. G. Murch, P. Temple-Smith P, and C. J. Dawes, "Friction-stir butt welding, GB Patent No. 9125978.8," International patent application No. PCT/GB92/02203, 1991.

[10] W. Woo and H. Choo, "Softening behaviour of friction stir welded Al 6061-T6 and Mg AZ31B alloys," Science and Technology of Welding and Joining, vol. 16, no. 3, pp. 267-272, 2011.

[11] P. Zhang, N. Guo, G. Chen et al., "Plastic deformation behavior of the friction stir welded AA2024 aluminum alloy," The International Journal of Advanced Manufacturing Technology, vol. 74, no. 5-8, pp. 673-679, 2014.

[12] T. Debroy, A. De, H. K. D. H. Bhadeshia, V. D. Manvatkar, and A. Arora, "Tool durability maps for friction stir welding of an aluminium alloy," Proceedings of the Royal Society A: Mathematical, Physical and Engineering Sciences, vol. 468, no. 2147, pp. 3552-3570, 2012.

[13] M. Indira Rani, R. N. Marpu, and A. C. S. Kumar, "A study of process parameters of friction stir welded AA 6061 aluminum alloy in $\mathrm{O}$ and T6 conditions," ARPN Journal of Engineering and Applied Sciences, vol. 6, no. 2, pp. 61-66, 2011.

[14] R. Nandan, T. DebRoy, and H. K. D. H. Bhadeshia, "Recent advances in friction-stir welding-process, weldment structure and properties," Progress in Materials Science, vol. 53, no. 6, pp. 980-1023, 2008.

[15] S. Rajakumar, C. Muralidharan, and V. Balasubramanian, "Establishing empirical relationships to predict grain size and tensile strength of friction stir welded AA 6061-T6 aluminium alloy joints," Transactions of Nonferrous Metals Society of China (English Edition), vol. 20, no. 10, pp. 1863-1872, 2010.

[16] W. Woo, H. Choo, D. W. Brown, Z. Feng, and P. K. Liaw, "Angular distortion and through-thickness residual stress distribution in the friction-stir processed 6061-T6 aluminum alloy," Materials Science and Engineering A, vol. 437, no. 1, pp. 64-69, 2006.

[17] W. H. Jiang and R. Kovacevic, "Feasibility study of friction stir welding of 6061-T6 aluminium alloy with AISI 1018 steel," Proceedings of the Institution of Mechanical Engineers, Part B: Journal of Engineering Manufacture, vol. 218, no. 10, pp. 13231331, 2004.

[18] L. E. Murr, G. Liu, and J. C. McClure, "A TEM study of precipitation and related microstructures in friction-stir-welded 6061 aluminium," Journal of Materials Science, vol. 33, no. 5, pp. 12431251, 1998.

[19] S. Rajakumar, C. Muralidharan, and V. Balasubramanian, "Predicting tensile strength, hardness and corrosion rate of friction stir welded AA6061-T6 aluminium alloy joints," Materials and Design, vol. 32, no. 5, pp. 2878-2890, 2011.

[20] R. Palanivel, P. Koshy Mathews, N. Murugan, and I. Dinaharan, "Effect of tool rotational speed and pin profile on microstructure and tensile strength of dissimilar friction stir welded AA5083-H111 and AA6351-T6 aluminum alloys," Materials and Design, vol. 40, pp. 7-16, 2012.

[21] K. Elangovan, V. Balasubramanian, and M. Valliappan, "Influences of tool pin profile and axial force on the formation of friction stir processing zone in AA6061 aluminium alloy," International Journal of Advanced Manufacturing Technology, vol. 38, no. 3-4, pp. 285-295, 2008.

[22] V. S. Gadakh and K. Adepu, "Heat generation model for taper cylindrical pin profile in FSW," Journal of Materials Research and Technology, vol. 2, no. 4, pp. 370-375, 2013.

[23] M. K. Sued, D. Pons, J. Lavroff, and E. H. Wong, "Design features for bobbin friction stir welding tools: development 
of a conceptual model linking the underlying physics to the production process," Materials and Design, vol. 54, pp. 632-643, 2014.

[24] M. Ilangovan, S. Rajendra Boopathy, and V. Balasubramanian, "Effect of tool pin profile on microstructure and tensile properties of friction stir welded dissimilar AA 6061-AA 5086 aluminium alloy joints," Defence Technology, vol. 11, no. 2, pp. 174-184, 2015.

[25] K. Ramanjaneyulu, G. Madhusudhan Reddy, A. Venugopal Rao, and R. Markandeya, "Structure-property correlation of AA2014 friction stir welds: role of tool pin profile," Journal of Materials Engineering and Performance, vol. 22, no. 8, pp. 2224-2240, 2013.

[26] V. S. Gadakh, A. Kumar, and G. J. Vikhe Patil, "Analytical modeling of the friction stir welding process using different pin profiles," Welding Journal, vol. 94, no. 4, pp. 115-124, 2015.

[27] S. Tikader, P. Biswas, and A. B. Puri, "A study on tooling and its effect on heat generation and mechanical properties of welded joints in friction stir welding," Journal of The Institution of Engineers (India): Series C, vol. 2016, 12 pages, 2016.

[28] H. I. Dawood, K. S. Mohammed, A. Rahmat, and M. B. Uday, "Effect of small tool pin profiles on microstructures and mechanical properties of 6061 aluminum alloy by friction stir welding," Transactions of Nonferrous Metals Society of China, vol. 25, no. 9, pp. 2856-2865, 2015.

[29] G. M. Dominguez Almaraz, J. C. Verduzco Juarez, R. García Hernández, and J. J. Villalón López, "Friction stir welding on aeronautical aluminum alloy 6061-T6," in Proceedings of the 25th International Materials Research Congress (IMRC '16), Cancún, Mexico, August 2016.

[30] D. Ortiz, M. Abdelshehid, R. Dalton et al., "Effect of cold work on the tensile properties of 6061, 2024, and $7075 \mathrm{Al}$ alloys," Journal of Materials Engineering and Performance, vol. 16, no. 5, pp. 515-520, 2007.

[31] T. Yokoyama, K. Nakai, and K. Katoh, "Tensile properties of AA6061-T6 friction stir welds and constitutive modeling in transverse and longitudinal orientations," Journal of Light Metal Welding and Construction, vol. 53, no. 8, pp. 19-28, 2015.

[32] N. Rajamanickam and V. Balusamy, "Effects of process parameters on mechanical properties of friction stir welds using design of experiments," Indian Journal of Engineering and Materials Sciences, vol. 15, no. 4, pp. 293-299, 2008.

[33] A. Karam, T. S. Mahmoud, H. M. Zakaria, and T. A. Khalifa, "Friction stir welding of dissimilar A319 and A413 cast aluminum alloys," Arabian Journal for Science and Engineering, vol. 39, no. 8, pp. 6363-6373, 2014.

[34] A. Dorbane, G. Ayoub, B. Mansoor, R. Hamade, G. Kridli, and A. Imad, "Observations of the mechanical response and evolution of damage of AA 6061-T6 under different strain rates and temperatures," Materials Science and Engineering: A, vol. 624, pp. 239-249, 2015.

[35] H.-B. Chen, K. Yan, T. Lin, S.-B. Chen, C.-Y. Jiang, and Y. Zhao, "The investigation of typical welding defects for 5456 aluminum alloy friction stir welds," Materials Science and Engineering A, vol. 433, no. 1-2, pp. 64-69, 2006.

[36] C. Hamilton, S. Dymek, and M. Blicharski, "A model of material flow during friction stir welding," Materials Characterization, vol. 59, no. 9, pp. 1206-1214, 2008.

[37] Q. Yang, S. Mironov, Y. S. Sato, and K. Okamoto, "Material flow during friction stir spot welding," Materials Science and Engineering A, vol. 527, no. 16-17, pp. 4389-4398, 2010.
[38] X. He, F. Gu, and A. Ball, "A review of numerical analysis of friction stir welding," Progress in Materials Science, vol. 65, pp. 1-66, 2014.

[39] R. S. Mishra and Z. Y. Ma, "Friction stir welding and processing," Materials Science and Engineering R: Reports, vol. 50, no. 1-2, pp. 1-78, 2005.

[40] J. S. Leon and V. Jayakumar, "Investigation of mechanical properties of aluminium 6061 alloy friction stir welding," American Journal of Mechanical Engineering and Automation, vol. 1, no. 1, pp. 6-9, 2014. 

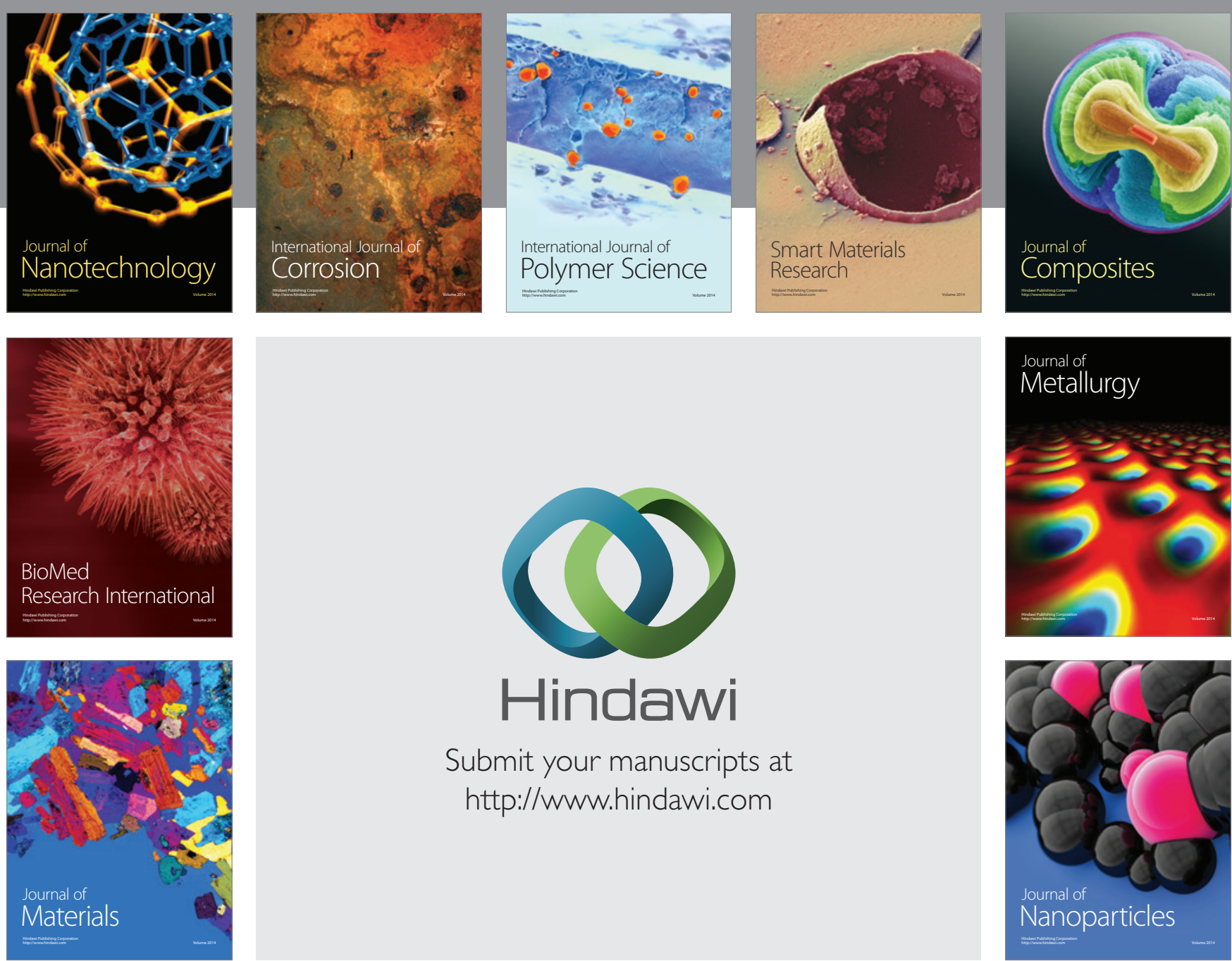

\section{Hindawi}

Submit your manuscripts at

http://www.hindawi.com

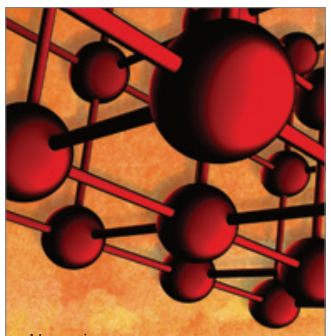

Materials Science and Engineering
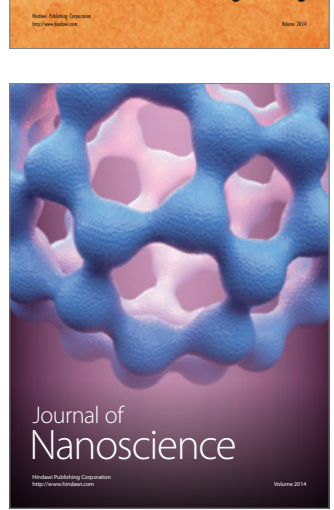
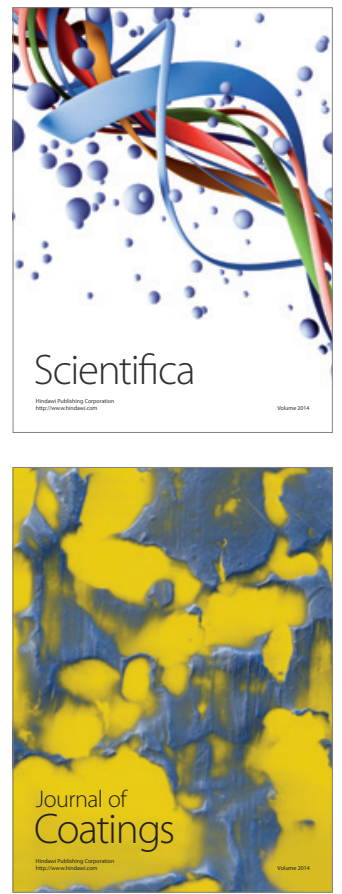
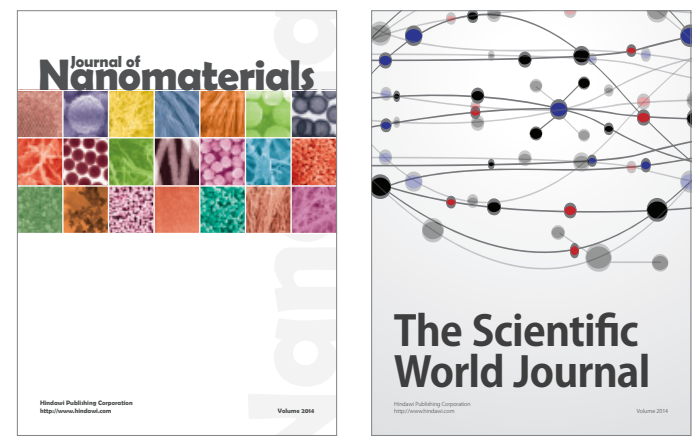

The Scientific World Journal
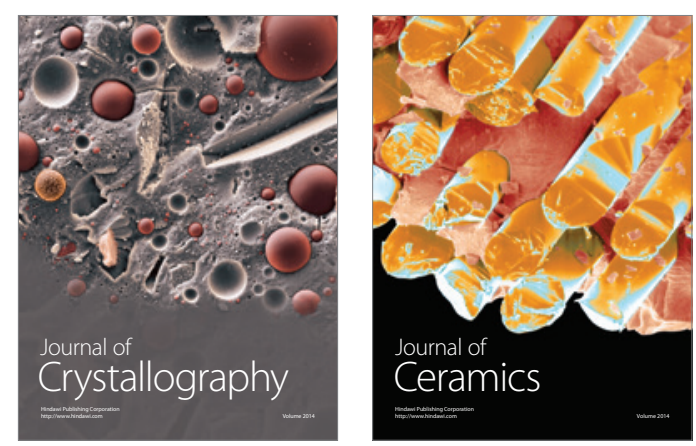
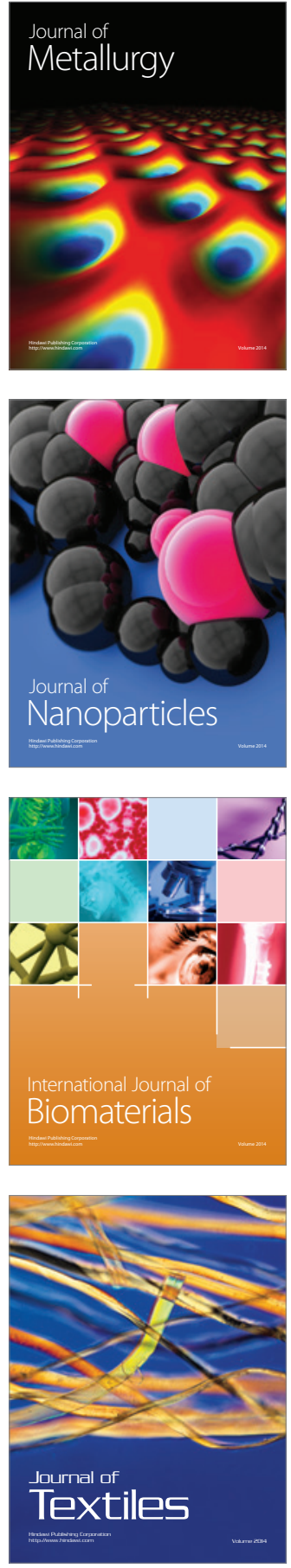